\title{
Inhibition of Ck1 affects Viability and Survival of Glioblastoma Cells
}

\author{
Joachim Bischof ${ }^{1 *}$, Anna-Laura Kretz ${ }^{1}$, Uwe Knippschild ${ }^{1}$, Pengfei Xu1 and Timo Burster ${ }^{2}$ \\ ${ }^{1}$ Department of General and Visceral Surgery, Ulm University Hospital, Germany \\ ${ }^{2}$ Department of Biology, Nazarbayev University, Kazakhistan
}

Received: January 24, 2018; Published: February 06, 2018

*Corresponding author: Joachim Bischof, Department of General and Visceral Surgery, Ulm University Hospital, Albert-Einstein-Allee 23, 89081 Ulm, Germany, Tel: 0049731500 53589; Email: joachim.bischof@uniklinik-ulm.de

\begin{abstract}
Glioblastoma multiforme (GBM) is the most common and lethal primary brain tumor with an inevitable fatal outcome. However, the complex network of dysregulated pathways in glioblastoma development and progression remains to be poorly understood. Consequently,novel approaches for the treatment of glioblastoma are seriously needed and the search for new target molecules for pharmacologic intervention is in the focus of research. Since it is known that CK1 isoforms are involved in Wnt/ $\beta$-catenin and sonic hedgehog signal transduction pathways, which are often dysregulated in glioblastoma cells, inhibition of CK1 isoforms might hold therapeutic potential. Therefore, two previously characterized CK1 isoform-selective difluoro-dioxolo-benzoimidazole derivatives were investigated on their effects on the viability of glioblastoma cell lines. Compound 2 showed major effects on the tested cells with EC50 values below $100 \mathrm{nM}$ in most of the analyzed glioblastoma cell lines. Cell cycle analyses underlined the observation that compound 2 is most effective since treatment with compound 2 induced cell death in up to $57 \%$ of the analyzed cells. In conclusion, our data point to a high therapeutic potential of CK1 isoform-selective inhibitors for the treatment of glioblastoma..
\end{abstract}

Keywords: Ck1: Casein Kinase 1; Gbm: Glioblastoma; Small Molecule Inhibitor, Kinaseinhibitor, Mtt Assay, Flow Cytometry, Cell Cycle

Abbreviations: Ck1: Casein Kinase 1; Dmso: Dimethylsulfoxide; Ec50: Half Maximal Effective Concentration; Gbm: Glioblastoma Multiforme; Mtt, 3-(4,5-Dimethylthiazol-2-Yl)-2,5-Diphenyltetrazolium Bromide; Shh: Sonic Hedgehog

\section{Introduction}

In comparison to other fatal diseases cancer of the brain and the nervous system is quite rare. The majority of the primary intrinsic tumors which not arise from meninges or nerves is derived from glia cells and is therefore named "gliomas". Complete tumor resection is usually impossible because these tumors penetrate deep into the brain leading to damage in brain circuits, alterations of blood vessels and blood flow, and tissue swelling. Patients with the diagnosis of the most common and deadly form "glioblastoma multiforme" (GBM) survive only in rare cases $(<30 \%)$ for more than two years after diagnosis even with the most aggressive treatments. Despite 30 years of research comprising diverse agents and delivery systems the survival rate for GBM patients has not changed significantly [1]. For the development of novel therapies, it is desirable to gain a deeper understanding of the biology of GBM. So far, the influence of different pathways, interacting in a concerted manner in GBM development has not been fully understood. Wnt/ $\beta$-catenin (Wnt) and sonic hedgehog (SHH) signaling are among the major pathways, which are known to be dysregulated in higher grade brain tumors and are responsible for cellular migration, proliferation, and improved survival of tumor cells. Furthermore, Wnt and SHH signaling contribute to maintenance, proliferation, and clonogenicity of glioma cancer stem cells playing a crucial role in initiation and pathogenesis of the malignancy reviewed in [2]. As central signal transduction molecules, protein kinases of the CK1 family are involved in regulating the activities of Wnt and SHH signaling pathways and therefore, the members of the CK1 family represent promising new drug targets [3].

The CK1 family is an independent phylogenetic family of highly conserved, monomeric, and second messenger-independent serine/ threonine-specific kinases. Six CK1 isoforms $(\alpha, \gamma 1-3, \delta$, and $\varepsilon)$ as well as several splice variants were identified in humans (Knippschild, Kruger et al.2014). Members of the CK1 family phosphorylate numerous proteins which are involved in the regulation of important cellular processes like proliferation, differentiation, apoptosis, DNA repair, and chromosomal segregation. Mutations and/or dysregulation of CK1 isoforms (expression and/or activity) might be critically involved in tumorigenesis [3,4]. Inhibition of CK1 family members can be achieved by various specific small molecule 
inhibitor compounds and peptides which have been described in literature in recent years $[3,5,6]$. Inhibition of CK1 isoforms has already shown beneficial effects on the viability and proliferation of tumor cells in vitro [5-11]. as well as in vivo [12-14]. Here, we report novel effects of two previously described CK1 isoformselective inhibitors on established glioblastoma cell lines.

\section{Materials and Methods}

Table 1: Characteristics of and culture conditions for the used human glioblastoma cell lines.

\begin{tabular}{|c|c|c|c|c|c|}
\hline Cell line & Cell type & Growth medium & Doubling time & Morphology & References \\
\hline SNB-19 & astrocytoma & $\begin{array}{c}\text { 90\% DMEM } \\
10 \% \text { FBS } \\
1 \% \text { Pen-Strep } \\
1 \% \text { L-glutamine }\end{array}$ & ca. $24 \mathrm{~h}$ & $\begin{array}{l}\text { adherent fibroblastic } \\
\text { cells, monolayer, } \\
\text { contact inhibition }\end{array}$ & $\begin{array}{c}\text { (Ponten and Macintyre } \\
\text { 1968, } \\
\text { Beckman, Beckman } \\
\text { et al. } \\
\text { 1971) }\end{array}$ \\
\hline DK-MG & glioma & $\begin{array}{c}90 \% \text { RPMI } \\
10 \% \text { FBS } \\
1 \% \text { Pen-Strep } \\
1 \% \text { L-glutamine } \\
\end{array}$ & ca. $50 \mathrm{~h}$ & $\begin{array}{l}\text { spindle, fibroblast-like } \\
\text { cells, adherent, } \\
\text { monolayer }\end{array}$ & $\begin{array}{c}\text { (Kruse, Varella- Garcia } \\
\text { et } \\
\text { al. 1998) }\end{array}$ \\
\hline LN-405 & astrocytoma & $\begin{array}{c}\text { 90\% DMEM } \\
10 \% \text { FBS } \\
1 \% \text { Pen-Strep } \\
1 \% \text { L-glutamine } \\
\end{array}$ & ca. $60 \mathrm{~h}$ & fibroblastic, monolayer & $\begin{array}{c}\text { (Bodmer, Strommer } \\
\text { et al. } \\
\text { 1989) }\end{array}$ \\
\hline U-138-MG & glioblastoma & $\begin{array}{c}90 \% \text { Ham'sF10 } \\
10 \% \text { FBS } \\
1 \% \text { Pen-Strep } \\
1 \% \text { L-glutamine }\end{array}$ & ca. $70 \mathrm{~h}$ & $\begin{array}{l}\text { fibroblastoid fusiform } \\
\text { cells, mono-or } \\
\text { multilayer }\end{array}$ & $\begin{array}{c}\text { (Ponten and Macintyre } \\
1968, \\
\text { Beckman, Beckman } \\
\text { et al. } \\
\text { 1971) }\end{array}$ \\
\hline
\end{tabular}

Cell lines The established human glioblastoma cell lines used in this study were ordered from the German Collection of Microorganisms and Cell Cultures (Leibniz Institute DMSZ), Braunschweig, Germany. An overview of the characteristics and culture conditions of the used cell lines is given in Table 1. MTT Viability Assay MTT (3-(4,5-dimethylthiazol-2-yl)2,5-diphenyltetrazolium bromide) assays were performed in 96-microwell format in order to analyze possible effects of tested inhibitor compounds on cell proliferation or cytotoxic influence leading to cell death. Cells were seeded in a density of $5 \times 104$ viable cells/ml (SNB-19) or 1 x 105 cells/ml (DK-MG, LN-405, U-138) in a total volume of $200 \mu \mathrm{l}$ per well and allowed to attach for $24 \mathrm{~h}$ under standard cultivation conditions. Cells were treated with the indicated concentrations of inhibitor compounds. Cells treated with DMSO (used as solvent for inhibitor compounds) served as controls. After $48 \mathrm{~h}$ cells were incubated for $4 \mathrm{~h}$ with $10 \mu \mathrm{l}$ MTT solution (5 $\mathrm{mg} / \mathrm{ml}$ in PBS) per well. MTT-containing medium was removed and $100 \mu \mathrm{l}$ acidified isopropanol $(0.04 \mathrm{~N} \mathrm{HCl}$ in isopropanol) were added per well and while shaking the plates for $30 \mathrm{~min}$ the formed precipitate was solubilized. The resulting solution was finally measured spectrophotometrically at a wavelength of $570 \mathrm{~nm}$ and a reference wavelength of $650 \mathrm{~nm}$. GraphPad Prism 6 software was used to generate charts for cell viability. The results obtained from treated cells were normalized by using the mean optical density of the DMSO-treated cells as reference. Each experiment was performed with four biological replicates. In order to determine the half maximal effective concentration (EC50) for the tested inhibitor compounds cells were first treated for $48 \mathrm{~h}$. Then the inhibitor-containing medium was exchanged and cells were treated for another $72 \mathrm{~h}$ prior to photometric analysis. Cell Cycle Analysis For performing cell cycle analyses 5 x 105 viable cells/well (DKMG, LN-405, U-138) or 2 x 105 cells/well (SNB-19), respectively, were seeded in 6-well cell culture plates and allowed to attach for $24 \mathrm{~h}$. Cells were then treated with $20 \mu \mathrm{M}$ concentration of inhibitor compounds. Untreated and DMSO-treated cells served as controls. After $48 \mathrm{~h}$ cells were washed once with PBS prior to preparation for cell cycle analysis using the CycleTEST ${ }^{\mathrm{TM}}$ PLUS DNA Reagent Kit (BD Bioscience) as indicated in the manufacturer's protocol. Briefly, 1 $\mathrm{ml}$ of buffer solution was added per well and the cells were scraped off the surface and collected by centrifugation at $400 \mathrm{x}$ g for $5 \mathrm{~min}$ at room temperature. The cell pellet was re-dissolved in $200 \mu \mathrm{l}$ of Solution A (trypsin buffer) by flicking the tube. After an incubation at room temperature for $10 \mathrm{~min} 180 \mu \mathrm{l}$ of Solution B (trypsin inhibitor and RNase buffer) were added and gently mixed. After incubating the suspension for another $10 \mathrm{~min}$ at room temperature $180 \mu \mathrm{l}$ of chilled Solution C (propidium iodide stain solution) were added to the mixture and a final incubation step was performed on ice for $10 \mathrm{~min}$. Prior to measurement samples were filtered through a 50- $\mu$ mnylon mesh and stored on ice until analysis in a FACScan flow cytometer (Becton-Dickinson, Franklin Lakes, USA). For each sample 20,000 events were counted. Doublets were discriminated and resulting data were used to study cell cycle distribution and DNA aneuploidy.

\section{Results}

Viability of glioblastoma cell lines is affected by inhibition of CK1 Since glioblastoma multiforme is highly resistant to common combined radio- and chemotherapy, there is a serious need to 
identify new targets for drug development. As indicated by a database research mRNA levels of CK1 $\delta$ as well as other CK1 isoforms is increased in glioblastoma tumor tissue samples [4]. With the purpose to test whether members of the CK1 family actually represent possible targets for new therapeutic approaches for glioblastoma, two previously published CK1 isoform-selective small molecule inhibitors were tested for their effects on established glioblastoma cell lines. These two difluoro-dioxolo-benzoimidazole derivatives, compounds Richter-1 (afterwards referred to as compound 1) and Richter-2 (compound 2), respectively, were previously characterized as highly potent inhibitors displaying remarkable selectivity toward CK1 $\delta$ and inhibited cell proliferation of different tumor cell lines [10]. In order to determine whether these inhibitors are also able to affect the viability of various glioblastoma cell lines SNB-19, DK-MG, LN-405, and U-138-MG cells were initially treated with $20 \mu \mathrm{M}$ of each compound for $48 \mathrm{~h}$. Following treatment with compound 1 only minor effects on cell viability could be observed for all tested glioblastoma cell lines. The strongest effect was observed for the fast-growing cell line SNB19 , which showed a reduction of cell viability by $18 \%$. In contrast, treatment with compound 2 induced more remarkable reduction of cell viability in all cell lines while best effects could be determined for cell lines SNB-19 and DK-MG showing reduction of cell viability by $72 \%$ and $56 \%$, respectively (Figure 1). SNB-19, DK-MG, LN-405, and U-138-MG cells were either treated with DMSO as a negative control or with $20 \mu \mathrm{M}$ concentration of compounds 1 or 2 as described in Materials and Methods. Cell viability was determined via MTT assay. The bar graph was generated using GraphPad Prism 6. Data are presented as mean \pm SD, n 4 .

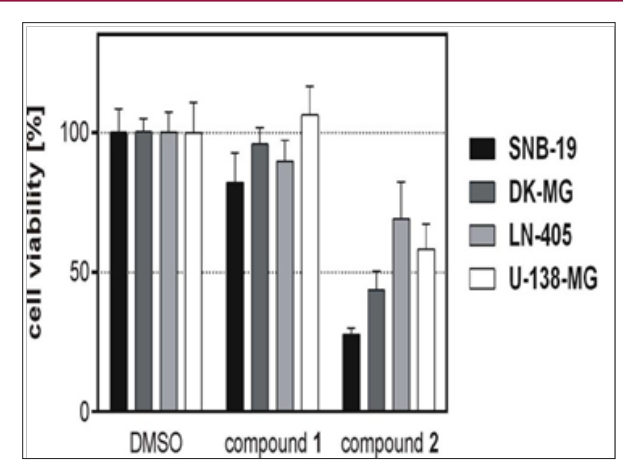

Figure 1: CK1 isoform-selective inhibitor compounds affect cell viability of various glioblastoma cell lines.

Further on, EC50 (half maximal effective concentration) values for the treatment of cell lines SNB-19, DK-MG, LN-405, and U-138-MG with compound 2 were determined in MTT viability assays. Therefore, cells were treated with a dilution series of this inhibitor for a total duration of five days. For all cell lines EC50 values in the submicromolar range could be determined. While cell lines U-138-MG and LN-405 exhibited EC50 values of 0.52 and $0.16 \mu \mathrm{M}$, values of 90 and $60 \mathrm{nM}$ were calculated for DK-MG and SNB-19, respectively (Figure 2). Dose-response relationships were analyzed for the CK1 $\delta$-selective inhibitor compound 2 in SNB-19 (A), DK-MG (B), LN-405 (C), and U-138-MG cells (D). Cells were treated with a dilution series of the inhibitor compound for a total duration of five days after seeding the cells and end-point data were obtained from MTT viability assays. Calculation of dose-response curves and half maximal effective concentration (EC50) values was performed using GraphPad Prism 6. Data are presented as mean \pm $\mathrm{SD}, \mathrm{n}=4$. CK1 isoform-specific inhibitors as effective inducers of glioblastoma cell death in subsequent experiments flow cytometry was used to analyze the apoptosis rate and cell cycle distribution of glioblastoma cell lines SNB-19 and DK-MG, which showed most sensitive responses to inhibitor treatment in the previous experiments. Cells were exposed to $20 \mu \mathrm{M}$ of the CK1 $\delta$-selective inhibitor compound 2 for $48 \mathrm{~h}$, stained with propidium iodide as described in the materials and methods section, and the cellular DNA content was finally measured by flow cytometry. For both cell lines non-treated and DMSO-exposed cells displayed normal cell cycle distribution of asynchronously proliferating cells with only a small amount of dead cells (SubG1 less than 1\%). In both cell lines, treatment with compound 2 led to significant changes in cell cycle distribution. In SNB-19 cells inhibitor treatment resulted in a massive increase in the amount of dead cells (52.91\%; Figures $3 \mathrm{~A}$ \&3C).

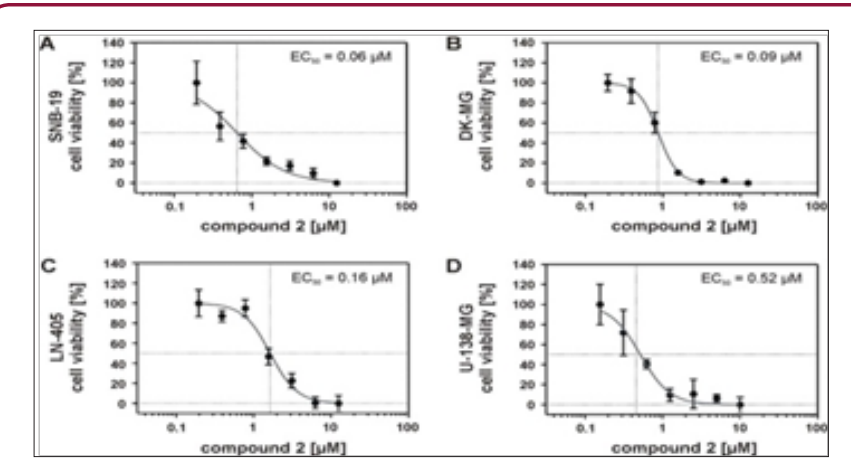

Figure 2: Low EC50 values can be obtained for the treatment of glioblastoma cell lines with compound 2.

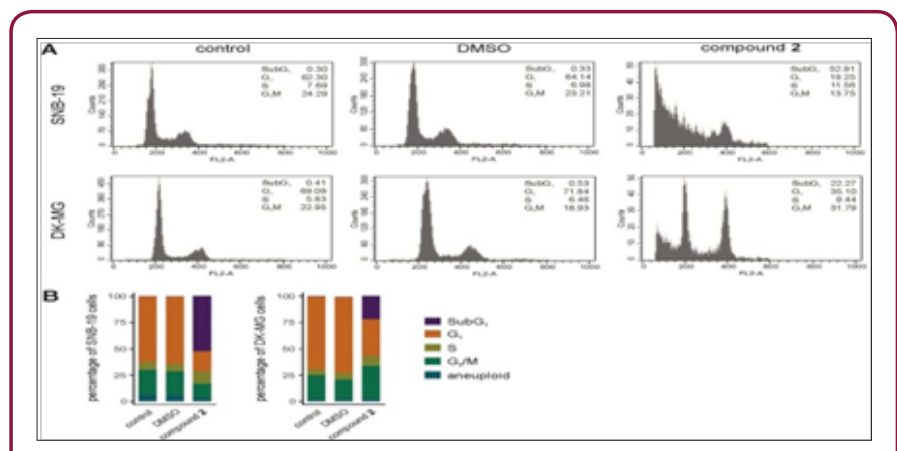

Figure 3: Treatment with compound 2 affects survival and cell cycle distribution of glioblastoma cell lines.

In DK-MG cells both, the amount of dead cells $(22.27 \%)$ as well as the amount of cells in G2/M phase (31.79\%), was increased (Figures 3B \& 3C). SNB-19 and DK-MG cells were treated for $48 \mathrm{~h}$ with the CK1 $\delta$-selective inhibitor compound 2 at a concentration of $20 \mu \mathrm{M}$. (A) Schematic representation of cell cycle distribution, analyzed by flow cytometry after treatment with compound 2 in comparison to untreated cells (control) and cells exposed to DMSO. Presented data are representative for analyses at least performed 
in triplicate. (B) Distribution of cells to different cell cycle phases (SubG1, G1, S, G2/M, aneuploid cells) is shown as DNA content histograms for SNB-19 and DK-MG cells.

\section{Discussion}

Glioblastoma multiforme is the most common and most deadly type of primary brain tumors in adults. Despite multimodal therapy regimens comprising surgery, radiotherapy, and chemotherapy the median survival of patients remains poor. Therefore, interest has increased in identifying new targets for drug development. Members of the CK1 family represent such a new target. In the present study, we demonstrated that the tested difluoro-dioxolobenzoimidazole derivative compound 2 led to significantly reduced cell viability and altered cell cycle distribution in established glioblastoma cell lines. We previously reported on compounds 1 and 2 as highly potent and CK $1 \delta$-selective small molecule inhibitors, which significantly affect the viability of established tumor cell lines when used in a low concentration range [10]. In comparison to the lead compound 1, which showed strongest inhibitory effects on CK1 isoform $\delta$ in vitro, treatment with the more advanced compound 2 however, resulted in more pronounced effects on cell viability and obtained EC50 values were in the submicromolar range with 0.105 $\mu \mathrm{M}$ for BxPC3 and $0.112 \mu \mathrm{M}$ for A2780 cells [10]. This massive improvement of intracellular availability for compound 2 was achieved by consequent improvement of molecule size, solubility, and cell permeability. Also in the present study, treatments with compound 2 led to more remarkable effects on cell viability and induction of cell death in the tested glioblastoma cell lines.

In general, these observations are in line with previously published results showing that CK1 inhibitors can influence colon, pancreatic, and lymphoma tumor cell kinetics by different mechanisms, resulting either in cell cycle arrest in G2/M phase or cell death, and that the effects of CK1-specific inhibitors depend on the cellular background of the cells, especially on their p53 status $[7,15,16]$. Differences in the cellular background might explain the differences in the sensitivity of the tested cell lines toward treatment with compound 1 or 2 . On the one hand cell lines SNB-19 and DK-MG might show more pronounced effects when treated with the inhibitor compounds because of their shorter doubling time compared to LN-405 and U-138-MG cells see Table 1. On the other hand, SNB-19 and DK-MG cells show different results in cell cycle distribution analyses because of differences in their p53 status. While DK-MG cells express wild-type p53 [17]. and treatment with compound 2 results in cell death as well as increased amount of cells arrested in G2/M, SNB-19 cells express mutant p53 [17-19]. and primarily respond with increased cell death following inhibitor treatment $[7,15,20]$. Thus, our data demonstrate that the cellular effects induced by the inhibitor treatment considerably depend on the cellular background, in particular on the mutation status of p53. In conclusion, our results for the first time showed that viability and survival of glioblastoma cells are massively affected following inhibition of CK1 $\delta$ by CK1 isoform-selective small molecule inhibitors. These data might represent a starting point for new therapeutic strategies for glioblastoma and highlight the role of the cellular background which necessarily needs to be considered for developing strategies for personalized medicine [21,23].

\section{Acknowledgement}

The authors would like to thank their collaboration partner, the biopharmaceutical company 4SC (Planegg-Martinsried, Germany), for kindly providing the tested inhibitor compounds.

\section{Funding Sources}

Joachim Bischof is financially supported by a grant of the medical faculty of Ulm University ("Bausteinprogramm").

\section{References}

1. Affronti ML, CR Heery, JE Herndon, JN Rich, DA Reardon, et al. (2009) Overall survival of newly diagnosed glioblastoma patients receiving carmustine wafers followed by radiation and concurrent temozolomide plus rotational multiagent chemotherapy. Cancer 115(15): 3501-3511.

2. Klaus A, W Birchmeier (2008) Wnt signalling and its impact on development and cancer. Nat Rev Cancer 8(5): 387-398.

3. Knippschild U, M Kruger J Richter, P Xu, B Garcia-Reyes, et al. (2014) The CK1 Family: Contribution to Cellular Stress Response and Its Role in Carcinogenesis. Front Oncol 4: 96.

4. Schittek B, T Sinnberg (2014) Biological functions of casein kinase 1 isoforms and putative roles in tumorigenesis. Mol Cancer 13: 231.

5. Halekotte J, L Witt, C Ianes, M Kruger, M Buhrmann, et al. (2017) Optimized 4,5-Diarylimidazoles as Potent/Selective Inhibitors of Protein Kinase CK1delta and Their Structural Relation to p38alpha MAPK. Molecules 22(4).

6. Dolde C, J Bischof, S Gruter, A Montada, J Halekotte, et al. (2018) A CK1 FRET biosensor reveals that DDX3X is an essential activator of CK1epsilon. J Cell Sci 131(1).

7. Peifer C, M Abadleh, J Bischof, D Hauser, V Schattel, et al. (2009) 3,4-Diaryl-isoxazoles and -imidazoles as potent dual inhibitors of p38alpha mitogen activated protein kinase and casein kinase 1delta. J Med Chem 52(23): 7618-7630.

8. Bischof J, J Leban, M Zaja, A Grothey, B Radunsky, et al. (2012) 2-Benzamido-N-(1H-benzo[d]imidazol-2-yl)thiazole-4-carboxamide derivatives as potent inhibitors of CK1delta/epsilon. Amino Acids 43: 1577-1591.

9. Bibian M, RJ Rahaim, JY Choi, Y Noguchi, S Schurer, et al. (2013) Developmentofhighlyselectivecaseinkinase 1delta/1epsilon(CK1delta/ epsilon) inhibitors with potent antiproliferative properties. Bioorg Med Chem Lett 23(15): 4374-4380.

10. Richter J, J Bischof, M Zaja, H Kohlhof, O Othersen, et al. (2014) Difluorodioxolo-benzoimidazol-benzamides as potent inhibitors of CK1 delta and epsilon with nanomolar inhibitory activity on cancer cell proliferation. J Med Chem 57(19): 7933-7946.

11. Monastyrskyi A, N Nilchan, V Quereda, Y Noguchi, C Ruiz, et al. (2017) Development of dual casein kinase 1delta/1epsilon (CK1delta/epsilon) inhibitors for treatment of breast cancer. Bioorg Med Chem 13:231.

12. Brockschmidt C, H Hirner, N Huber, T Eismann, A Hillenbrand, et al. (2008) Anti-apoptotic and growth-stimulatory functions of CK1 delta and epsilon in ductal adenocarcinoma of the pancreas are inhibited by IC261 in vitro and in vivo. Gut 57(6): 799-806.

13. Toyoshima M, HL Howie, M Imakura, RM Walsh, JE Annis, et al. (2012) Functional genomics identifies therapeutic targets for MYC-driven cancer. Proc Natl Acad Sci 109(24): 9545-9550.

14. Jaras M, PG Miller, LP Chu, RV Puram, EC Fink, et al. (2014) Csnk1a1 inhibition has p53-dependent therapeutic efficacy in acute myeloid leukemia. J Exp Med 211(4): 605-612. 
15. Stoter M, AM Bamberger, B Aslan, M Kurth, D. Speidel, et al. (2005) Inhibition of casein kinase I delta alters mitotic spindle formation and induces apoptosis in trophoblast cells. Oncogene 24(54): 7964-7975.

16. Winkler BS, F Oltmer, J Richter, J Bischof, P Xu, et al. (2015) CK1delta in lymphoma: gene expression and mutation analyses and validation of CK1delta kinase activity for therapeutic application. Front Cell Dev Biol 3: 9 .

17. Memmel S, VL Sukhorukov, M Horing, K Westerling, V Fiedler, et al. (2014) Cell surface area and membrane folding in glioblastoma cell lines differing in PTEN and p53 status. PLoS One 9(1): e87052.

18. Beckman G, L Beckman, J Ponten, B Westermark (1971) G-6-PD and PGM phenotypes of 16 continuous human tumor cell lines. Evidence against cross-contamination and contamination by HeLa cells. Hum Hered 21(3): 238-241.

19. Bodmer S, K Strommer, K Frei, C Siepl, N de Tribolet, et al. (1989)
Immunosuppression and transforming growth factor-beta in glioblastoma. Preferential production of transforming growth factorbeta 2. J Immunol 143(10): 3222-3229.

20. Huse JT, EC Holland (2010) Targeting brain cancer: advances in the molecular pathology of malignant glioma and medulloblastoma. Nat Rev Cancer 10(5): 319-331.

21. Kruse CA, M Varella-Garcia, BK Kleinschmidt-Demasters, GC Owens, EB Spector, et al. (1998) Receptor expression, cytogenetic, and molecular analysis of six continuous human glioma cell lines. In Vitro Cell Dev Biol Anim 34(6): 455-462.

22. Masui K, TF Cloughesy, PS Mischel (2012) Review: molecular pathology in adult high-grade gliomas: from molecular diagnostics to target therapies. Neuropathol Appl Neurobiol 38(3): 271-291.

23. Ponten J, EH Macintyre (1968) Long term culture of normal and neoplastic human glia. Acta Pathol Microbiol Scand 74(4): 465-486.

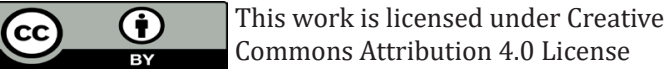

Submission Link: http://biomedres.us/submit-manuscript.php

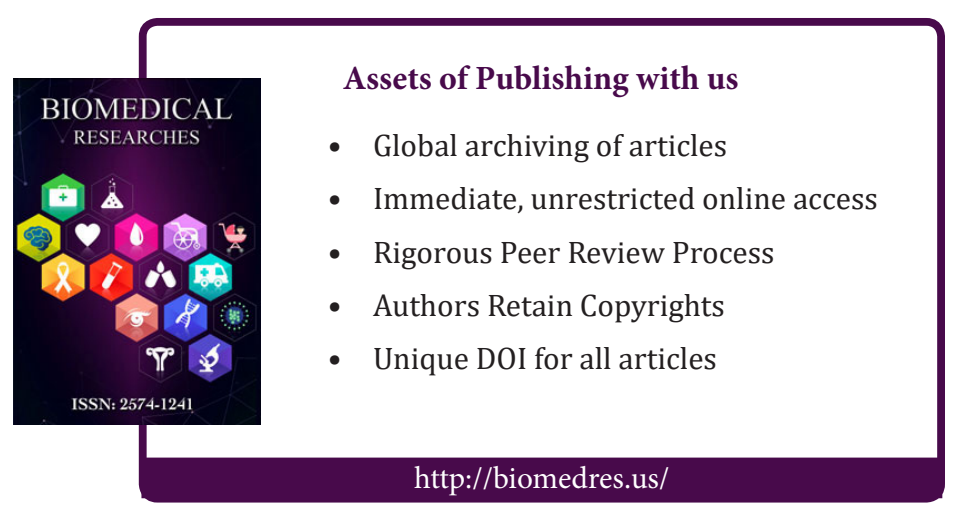

